\title{
"Now it's your turn to speak up!" - Burdens and Psychosocial Consequences of the COVID-19 pandemic for Austrian Children and Adolescents
}

\author{
Manuel Schabus ${ }^{1,2}$ \& Esther-Sevil Eigl $\left.\right|^{1,2}$ \\ 1 University of Salzburg; Department of Psychology; Laboratory for Sleep, Cognition and \\ Consciousness Research; Salzburg, Austria \\ ${ }^{2}$ University of Salzburg; Centre for Cognitive Neuroscience Salzburg (CCNS); Salzburg, Austria
}

Corresponding author:

Univ.-Prof. Dr. Manuel Schabus

Laboratory for Sleep, Cognition \& Consciousness Research

Hellbrunnerstraße 34

A-5020 Salzburg

Email: manuel.schabus@sbg.ac.at

Abstract: The survey "Now it's your turn to speak up!"1 evaluates the psychosocial burden and impairments of children and adolescents in Austria during the ongoing COVID-19 pandemic. Using an online-questionnaire, 5483 children and adolescents between 6 and 18 years shared their feelings, fears, worries and thoughts regarding the coronavirus pandemic. Most of them report a high degree of fear due to the current situation, with especially female participants being under more emotional strain than their male counterparts. Associated to this, the risk of a COVID-19-associated hospitalization is strongly overestimated, as previously found in adults. In addition, an alarming lack of perspective during the ongoing pandemic is evident across all age groups including the youngest participants aged 6-10 years. Feelings of fury, anger, loneliness, and sadness are reported much more frequently than previously. Last but not least, our study shows an alarming reduction of sleep quality and a drastic increase in self-reported sleep problems already in this young population. The results of the "Jetzt Sprichst Du!" survey emphasize the need for immediate action in order to limit the collateral damage caused on the psychosocial, developmental and health dimension as far as this is still possible today.

Keywords: Covid-19 pandemic, coronavirus, collateral damage, mental health, strain, fear

\section{Background}

The "Jetzt Sprichst Du!" survey was launched at the University of Salzburg on February 21,2021 , after the psychosocial collateral damage of the coronavirus pandemic and its measures became increasingly visible [1, 2]. Moreover, it is evident that especially children and adolescents are massively affected [3] and restricted in their development by the pandemic [4] and their voices have been heard little or not at all until now [5].

\footnotetext{
${ }_{1}^{1}$,Jetzt Sprichst Du!”; translated from German
} 
The study had been preceded by a survey of the general population's knowledge and attitudes regarding the corona pandemic from the age of eighteen ${ }^{2,3}$.

\section{Method}

Specifically, 5483 children and adolescents between the ages of 6 and 18 participated in the Austria-wide "Jetzt Sprichst Du!" survey conducted by the University of Salzburg between Feb. 21 and April 19, 2021. The survey was publicized via the Austrian Press Agency (APA), national TV (ORF), and various organizations that work with children and adolescents.

For data cleaning purposes, a plausibility check for data integrity was performed in addition to an age check before the data were analyzed. Specifically, answers to the question "What do you think: Out of 1000 students who are like you, how many of them will get seriously ill with Corona and end up in hospital in the next 12 months?" were compared to the same persons' answers to the associated question "How great do you think the risk is for you personally of having to go to the hospital because of Corona?". Persons who estimated that (i) max. 1 case (per 1000) would have to be hospitalized, were only included if they also rated the subjectively assessed risk of having to be hospitalized because of Corona as "minimal" or "not at all". Furthermore, persons who stated that (ii) at least 412 of 1000 (95th percentile) children would have to be hospitalized were only included in the final analysis if they also assessed their subjective risk of a Corona-related hospitalization as "very great" or "great". The final sample size after this data selection resulted in 5008 children and adolescents between 6 and 18 years of age who answered the survey up to the last question of the general part. Completion of an additional, second part of the survey was optional and included questions on sleep habits, activity level, and smartphone use. This part was completed by 2290 children and adolescents. It will be discussed in detail in a separate publication [6].

When evaluating the questions with ranks as an answer option, the frequencies of the first three categories were added up for the analysis. If a category was already selected as rank 1 , indicating that no other options were applicable (e.g., "I'm not really afraid"), only the first rank was reported.

\section{Results}

Of the 5008 children and adolescents, $60.9 \%$ were female, $37.9 \%$ male, and $1.2 \%$ diverse. The sample was divided into three age groups: 6-10-year-old "elementary school students" ( $n=949)$, 11-14-year-old "middle school students" $(n=1930)$, and 15-18-year-old adolescents $(n=2129)$.

When asked if the children and adolescents were "scared by the current situation with Corona," $48.1 \%$ of the girls and $35.9 \%$ of the boys answered that the situation scared them ("very much" or "somewhat"). Between the age groups, it is noticeable that especially the elementary school children show the greatest fears with regard to Corona and every second child feels frightened by the current situation ("very much" or "somewhat") (details see Fig.1).

\footnotetext{
2 See www.sleepscience.at for public relation activities on the "Corona" surveys.

3 Updated and translated from the German version (https://osf.io/9m36r).
} 


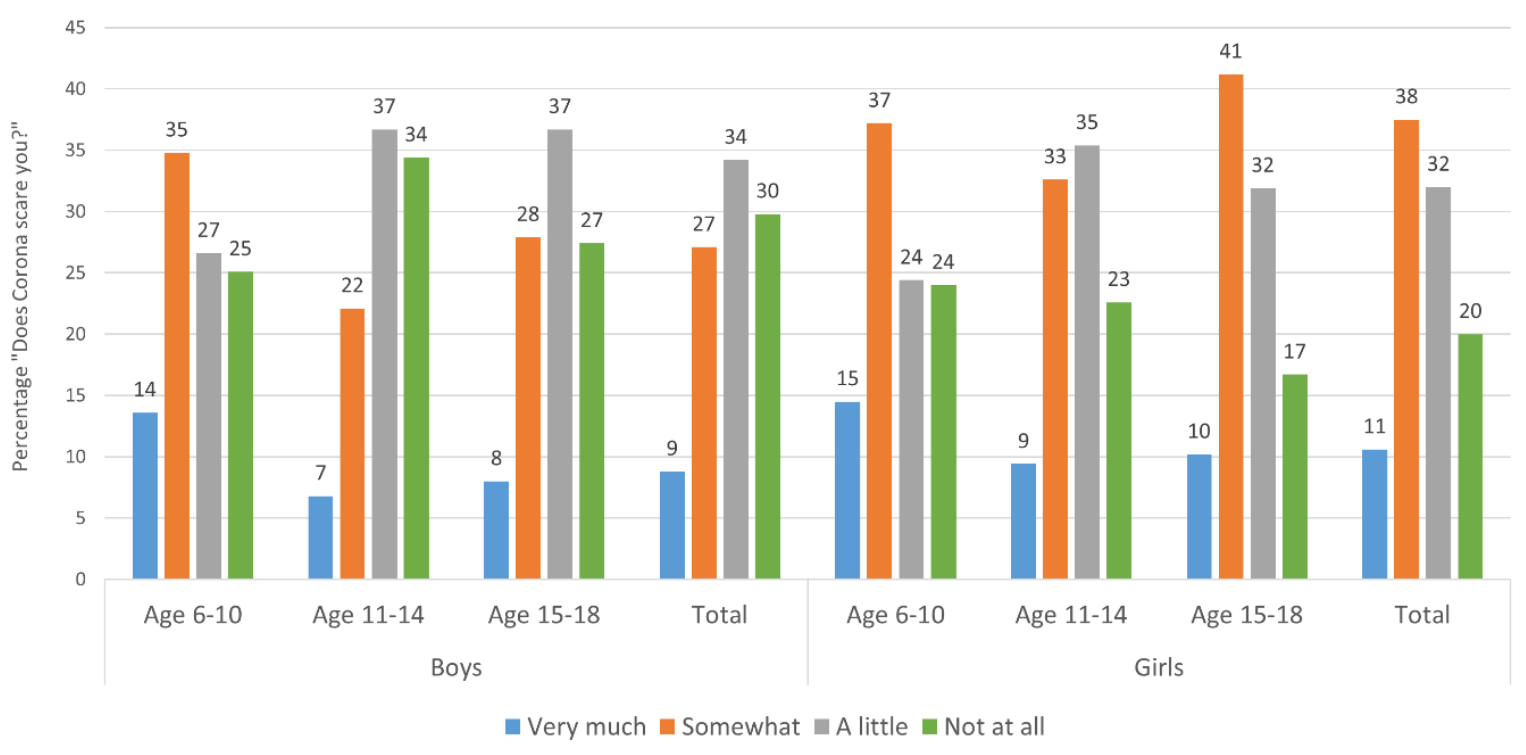

Figure 1. Distribution of children's and adolescents' answers to the question "Does the current situation with Corona scare you?" by age group and gender.

When asked about the nature of these fears, the following ones are primarily mentioned: "That it will be a long time before life will be like it was before" (54.4\%), "that life will not be like it was before at all" (50.1\%), "that parents, siblings or close relatives might die" $(48.1 \%)$, and that they will "no longer have the same future opportunities or job opportunities" as they had "before Corona" (36.8\%); only $8.8 \%$ of children and adolescents said they actually had none of these fears. The fear of no longer having the same future opportunities is particularly pronounced among young people (47.8\%; see Fig. 2 ).

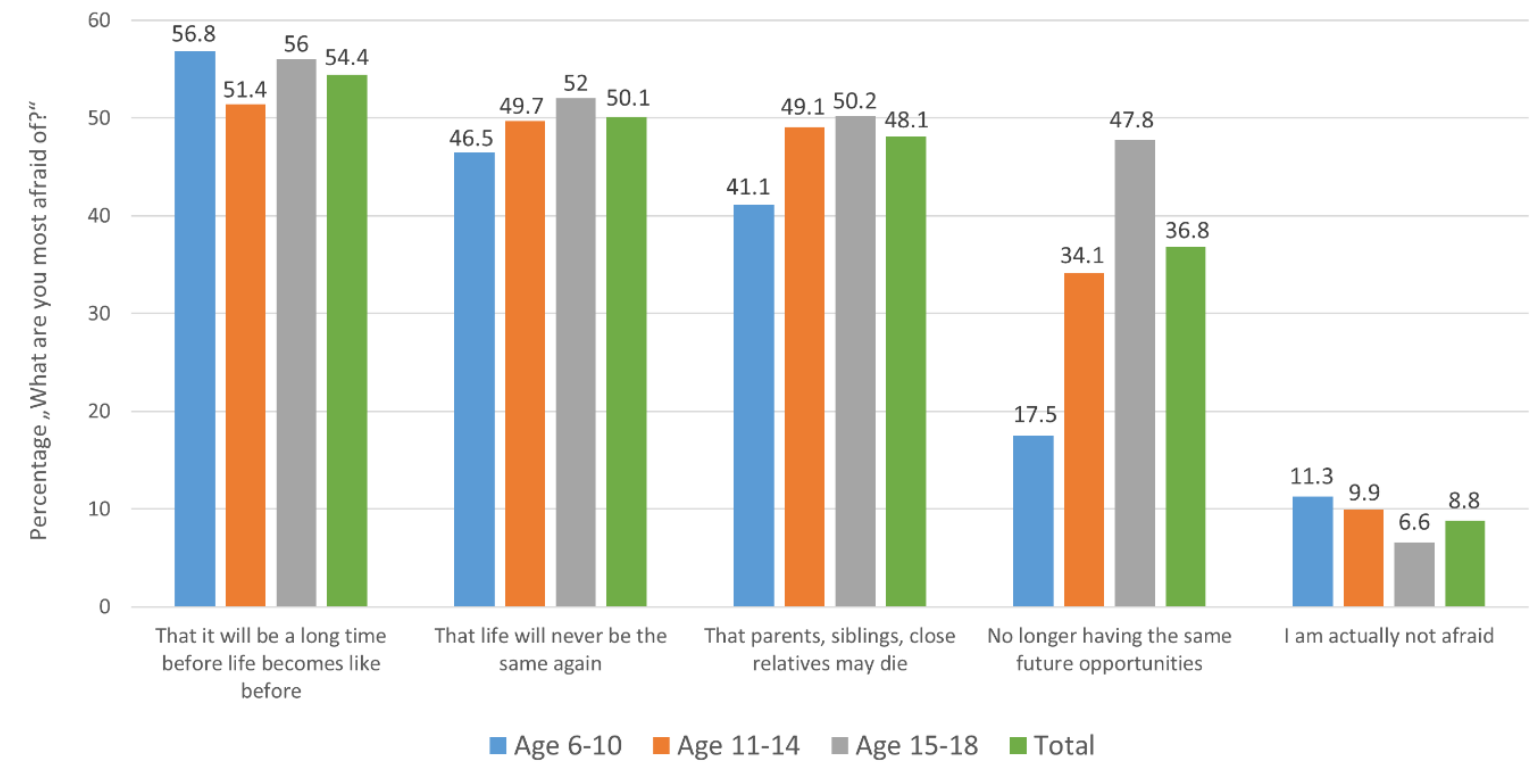

Figure 2. Distribution of children's and young people's answers to the question "What are you most afraid of - in relation to Corona?" by age group.

Next, we asked ourselves where the children and adolescents mainly get their information about Corona from. It is striking that elementary school students primarily obtain their information regarding Corona from their parents and family $(67.3 \%)$, whereas adolescents primarily use "social media" or the internet as a source of information (46.9\%); public television and school play a comparatively minor role (see Fig. 3). 


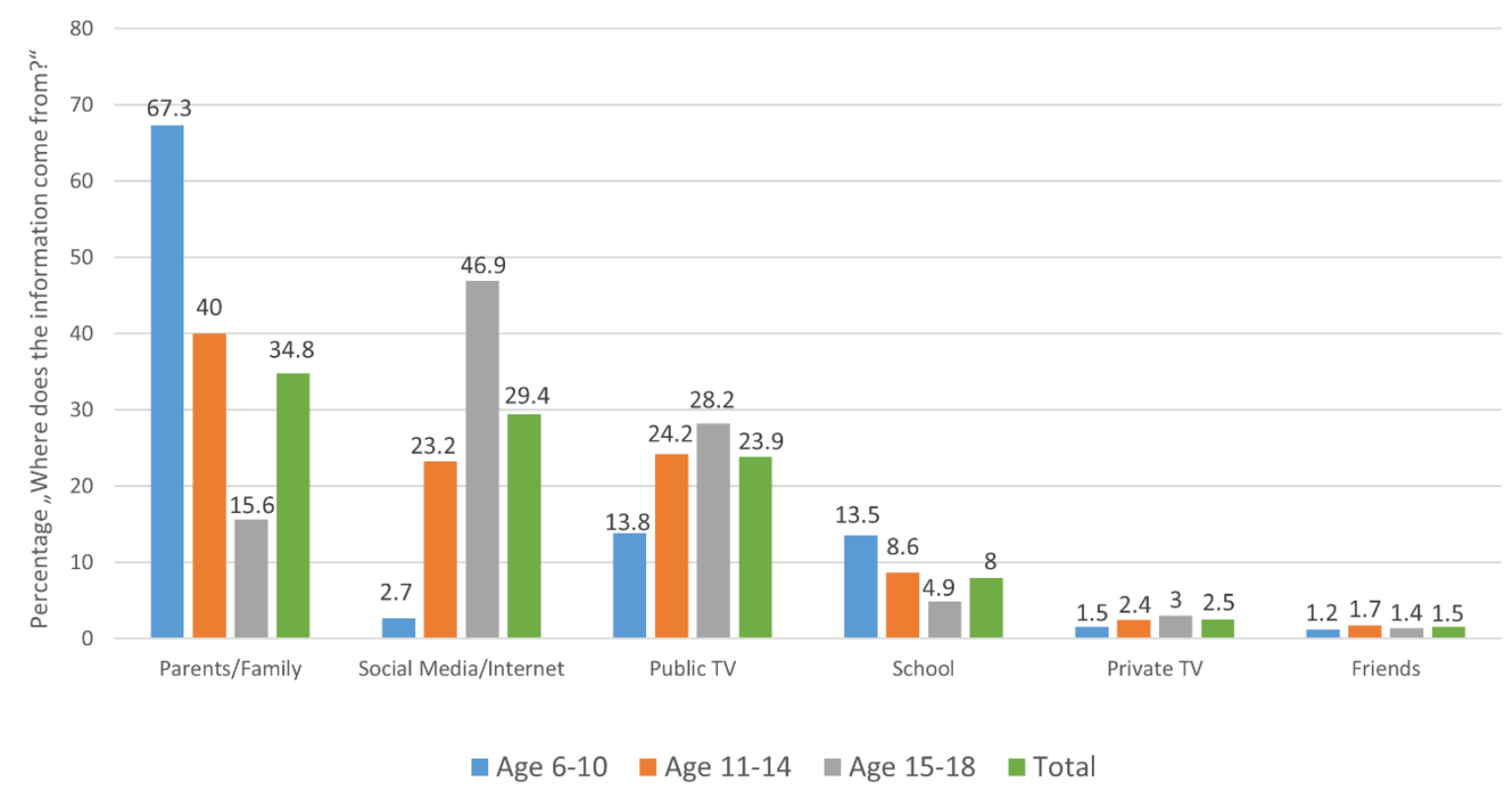

Figure 3. Distribution of children's and young people's responses to the question "Where do you mainly get your information about Corona from?" by age group

When children and adolescents are asked how they are doing compared to before Corona, $71.8 \%$ say they are doing "a lot" (25\%) or "a little" (46.8\%) worse than before Corona (see Figure 4A). When asked when they think "life will be relatively 'normal' again," $75.6 \%$ say they do not expect a return to normality until 2022 or later (cf. Fig. 4B). This is an expression of a certain lack of perspective among children and young people, which can be observed across all age groups.

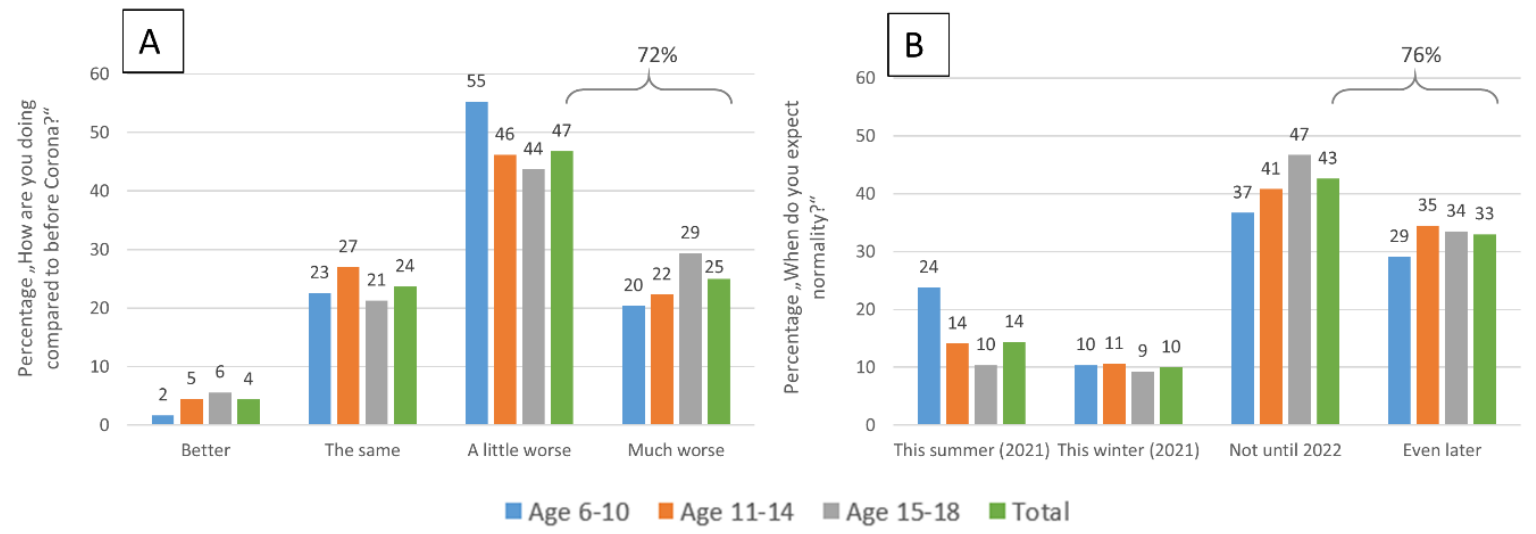

Figure 4. Distribution of children's and adolescents' responses to the question A) "How are you doing compared to before Corona?" and B) "When do you think life will be relatively "normal" again?" by age group.

Furthermore, the survey asked about the prevailing feelings since Corona. The most frequently mentioned feeling since Corona was "being angry and annoyed more often" (58.2\%), followed by "being lonely and alone more often" (46\%) and "being sad more often (42.7\%)." 15.6\% feel "good despite Corona" (13.6\%) or "even better" (2\%; see Fig. $5 \mathrm{~A})$. When asked about the things that children and adolescents miss most from normality, the answer most frequently given was "being able to meet friends without restrictions" (71.4\%), followed by "not having to wear masks and being able to see people's faces" (58.7\%), and "being able to do sports" (41.4\%). Adolescents report "going out" as the second most common response 

they miss everyday life "very much" (42.1\%) or "quite a bit" $(30.1 \%)$.

118

119

120

121

122

123

124

125

126

127

128

129

130

131

132

133

134

135

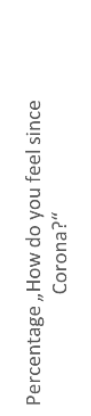

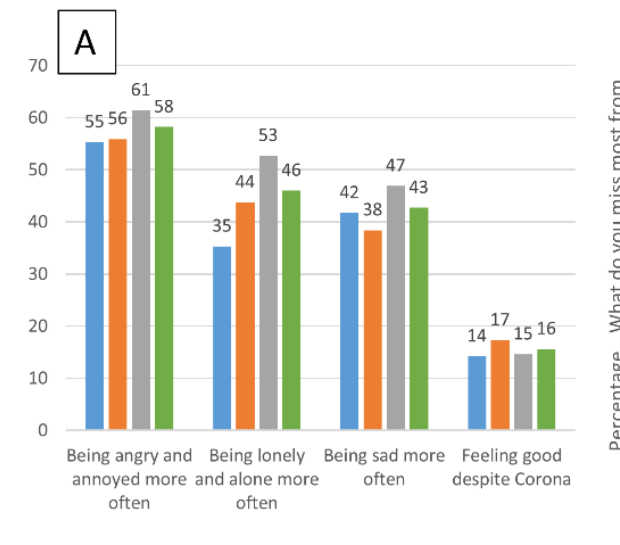

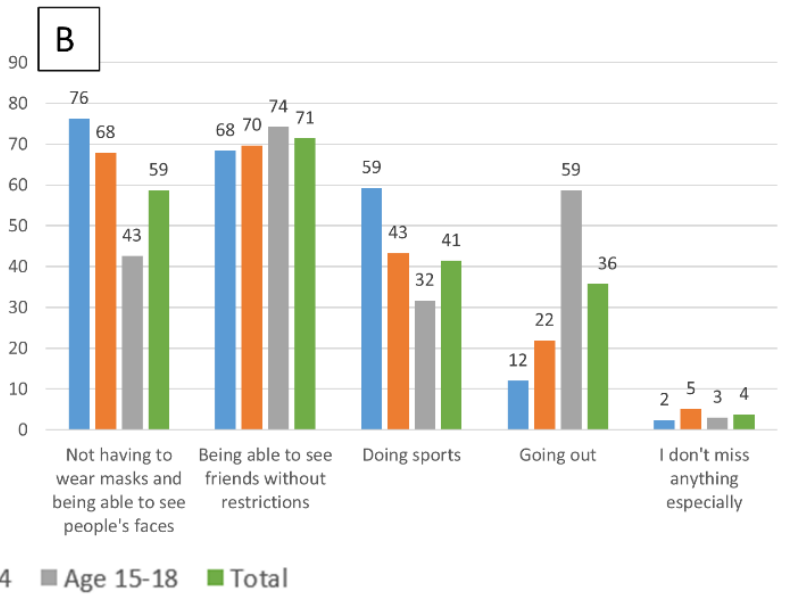

Figure 5. Distribution of children's and adolescents' answers to the question A) "How do you feel since Corona?" and B) "What do you miss most from normality?" by age group.

According to the children's and adolescents' assessment, the things that could help them most in the current situation are "meeting friends in person" (50.4\%), "spending time with family (49.2\%), and "spending time in nature" (39.3\%). $4.4 \%$ state that nothing actually helps them at the moment.

Furthermore, the children and adolescents were asked about their assessment of the risk posed by the coronavirus (SARS-CoV-2): "What do you think: Out of 1000 students who are like you, how many of them will get seriously ill with Corona and end up in the hospital in the next 12 months?" Interestingly, the risk of being hospitalized for SARS-CoV-2 infection is massively overestimated by children and adolescents and put at $1.2 \%-3.3 \%$, even though the risk in this young age group is less than 1 in $10,000(<0.01 \%)$ people with risk factors $[7,8]$ or less than 1 in $40,000(<0.003 \%)$ in children/adolescents without risk factors [7] (see Table 1$)$.

Table 1. Estimated risk of children and adolescents being hospitalized for SARS-CoV-2infection.

\begin{tabular}{llll} 
& Age 6-10 & Age 11-14 & Age 15-18 \\
\hline $\begin{array}{l}\text { 5\% trimmed mean } \\
\text { QCovid risk assessment (https://qcovid.org/) }\end{array}$ & $12(1.2 \%)$ & $33(3.3 \%)$ & $31(3.1 \%)$ \\
$\begin{array}{l}\text { for a COVID-19-associated hospitalization in a 19-year } \\
\text { old male person }\end{array}$ & $\begin{array}{l}1 \text { in 43478 }(0.0023 \%) \text { without risk factors } \\
1 \text { in 10753 (0.093\%) with diabetes type 1 and asthma }\end{array}$
\end{tabular}

Note: The University of Oxford (UK) Qcovid $\AA$ algorithm is an evidence-based model that incorporates factors such as age, sex, ethnicity, or pre-existing conditions to estimate the risk of COVID-19-associated hospitalization or death [7]. At https://qcovid.org this risk can be calculated for any individual. As an illustrative example, Table 1 shows the risk for a 19-year-old male $(180 \mathrm{~cm}, 80 \mathrm{~kg})$ with no pre-existing condition or with type 1 diabetes and asthma, and can be taken as an upper limit. For the latter COVID-19 associated death is estimated 1 in 200.000.

The fear that a parent or close relative will die - which is one of the primary fears in children and adolescents (Fig. 2) - also appears to be greatly exaggerated, since the actual risk of hospitalization according to Qcovid $\AA$ even for the "average grandparent" is approximately 1 in 469 cases (0.21\%) and that of death is approximately 1 in $1344(0.07 \%)$ 

$\mathrm{kg})$.

We also tried to understand whether it makes a difference whether children and adolescents live in an environment with Corona-related anxiety or with low-anxiety parents. For this purpose, the variable "What do your parents think about Corona?" was used for categorization, and children and adolescents who felt that their parents thought Corona was "very dangerous" or "dangerous" were assigned to the "anxious" group. Children who indicated that their parents considered Corona to be "not at all dangerous," "not very dangerous," or "similar to the flu" were defined as the "not anxious" group.

Across age groups, it appears that the anxious group was more likely to report having "almost not seen their relatives at all" (44.6\% vs. $33.6 \%$ for the non-anxious group), and being more afraid of the virus (47.1\% vs. $40.1 \%)$. When assessing the dangerousness of the SARSCoV-2 pathogen, $84 \%$ of the anxious group said Corona was "very dangerous" or "dangerous," with only $13 \%$ of the non-anxious group agreeing with this assessment. Also, three times more children in the anxious group estimated the risk of COVID-associated hospitalization as (very) high $(15.2 \%$ vs. $4.7 \%)$. A similar picture of overestimation of the risk for hospitalization emerges in the context of a query in absolute numbers, albeit to a different extent $(4.28 \% \mathrm{vs}$. $1.52 \%$ persons "who are just like you").

The greatest fears indicated by the children and adolescents also differ significantly in these two groups. Whereas the fearful group stated as their primary fear that "parents, siblings or close relatives could die" $(61 \%)$ or "that parents, siblings or close relatives could fall ill" (42.6\%; cf. fig. 6A), the non-anxious group is primarily concerned that "life might not be the same as before" $(61.1 \%)$ or that they might "no longer have the same future opportunities or job possibilities" as before Corona (44.8\%; cf. fig. 6B).

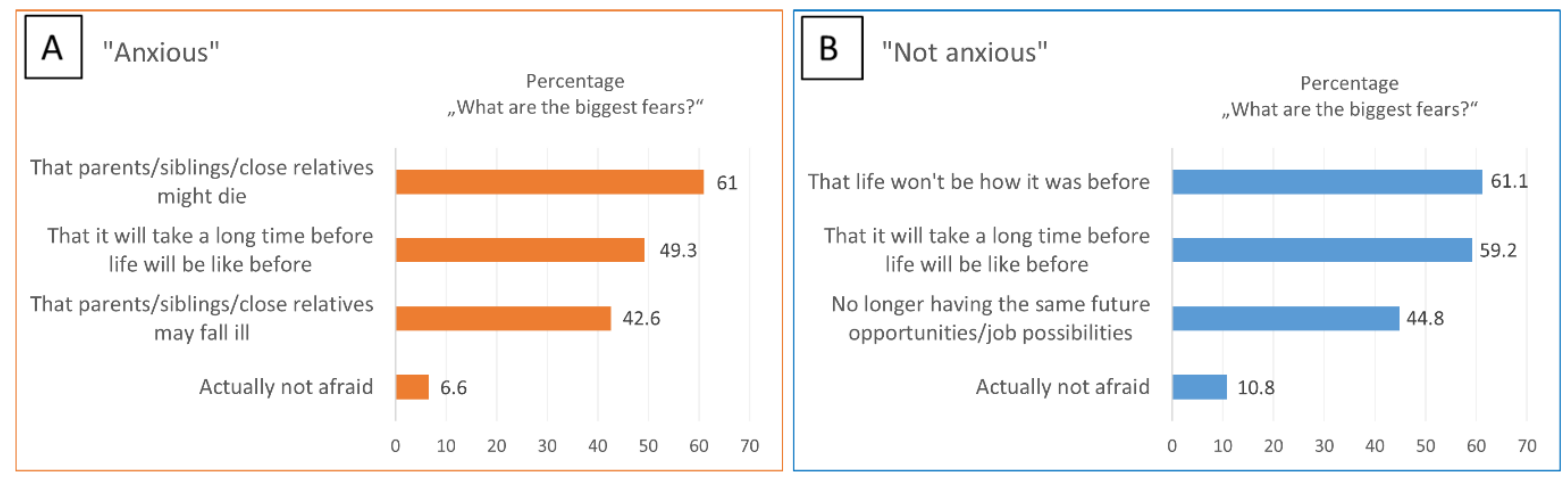

Figure 6. Distribution of children's and adolescents' answers to the question "What are you most afraid of - in relation to Corona?" in the group of A) "anxious" vs. B) "non-anxious" family environment. The group was formed according to the parents' fears and worries (assessed by the children/adolescents).

Comparing these two groups according to their predominant feelings since Corona, the surprising picture emerges that it is the children and adolescents of the non-anxious group who more frequently state that they feel "more often angry and annoyed" since Corona $(63.5 \%$ vs. $52.6 \%$ ). Presumably, it is difficult for these children to comprehend why they have to wear a mask in everyday school life, why they have to perform self-tests, or why strict distance rules apply, and therefore they are exposed to increased pressure in the system. In addition, the study shows that "feeling lonely and alone more often" increases noticeably from elementary school age to the group of adolescents. Here, it seems reasonable to assume that this is related to the fact that the Corona measures do not allow adolescents to meet their friends 
and peers, or only to a limited extent, whereas elementary school children spend even more time in the family itself anyway (cf. Table 2).

Table 2. Predominant feelings since Corona in the (Corona-) "anxious" vs. "non-anxious" groups.

\begin{tabular}{|lcccc|}
\hline "Anxious" & Total & Age 6-10 & Age 11-14 & Age 15-18 \\
\hline I am sad more often than before Corona & $n=2.456$ & $n=383$ & $n=922$ & $n=1.151$ \\
\hline I feel lonely and alone more often & 39.8 & 37.6 & 36.6 & 43.0 \\
\hline I feel angry and annoyed more often & 44.9 & 34.1 & 42.6 & 50.5 \\
\hline I feel good or even better despite Corona* & 52.6 & 43.8 & 49.8 & 57.9 \\
\hline & 19.4 & 19.6 & 21.0 & 18.1 \\
\hline "Not Anxious" & & & & Age 15-18 \\
\hline I am sad more often than before Corona & Total & Age 6-10 & Age 11-14 & $n=976$ \\
\hline I feel lonely and alone more often & $n=2.546$ & $n=566$ & $n=1.004$ & 51.4 \\
\hline I feel angry and annoyed more often & 45.4 & 44.4 & 40.0 & 55.5 \\
\hline I feel good or even better despite Corona* & 47.1 & 36 & 45.0 & 65.6 \\
\hline
\end{tabular}

Note: *Accumulation of response options "I feel good despite Corona" and "I feel even better than before".

In the second part of the questionnaire, which is only dealt with here as an example ( $n$ $=2290$ ), it is noticeable that the physical activities since Corona are stated as "very much less" or "less" by $74.8 \%$ of the children and adolescents. In addition, the amount of time that the participants spend in natural daylight also becomes shorter. It turns out to be reduced in $44.2 \%$ of the participants. On the other hand, the children as well as adolescents spend much more time with smartphones, tablets or PCs (85.0\%). Under these circumstances, sleep behavior among children and adolescents has also changed significantly since Corona.

More than one in three children (37\%) report poorer sleep quality since Corona. $38.9 \%$ of children even report now having problems with sleep, which is extremely unusual for this young age (6-18 yrs). Of those who report these sleep problems, $42.5 \%$ are plagued by difficulty falling asleep and $20.3 \%$ by difficulty staying asleep. In addition, 9 out of 10 children/adolescents (94.3\%) now go to bed later during the week. Age-wise, most Coronarelated sleep problems are seen in adolescents (45.3\%) and an accumulation of nightmares in the youngest (16.3\%).

\section{Summary}

In summary, an alarming picture of psychosocial health among children and adolescents emerges, highlighting the acute need for action. The particularly alarming and as yet unpublished (anonymous) comments of the children and adolescents in the "Jetzt Sprichst $\mathrm{Du}$ " survey paint a particularly clear picture here $\left(\mathrm{see}^{4}\right)$.

As an emblematic recommendation for action, we suggest "movement and encounter". Unfortunately, precisely these factors that would help the children and young people well through the pandemic are made impossible or only possible to a very limited extent due to the Corona measures.

From our point of view, the first priority must therefore be to strive for a rapid normalization, including leisure and sports activities for children and adolescents, and to take

\footnotetext{
${ }^{4}$ Siehe http://bit.ly/JetztSprichstDu supplements
} 
action now in order to prevent the worst. The effects of the often cited "lost year" for children and adolescents are difficult to assess today, both from a psychological and a psychotherapeutic point of view. However, it is probably undisputed that they will be substantial and will be reflected both in psychosomatic illnesses [9] and in behavioral problems such as truancy. In this respect, it would be advisable to consider an expansion of school psychology as well as educational and psychotherapeutic offers for children and adolescents already today.

Personally, we fear that in the psychosocial sector the worst is yet to come. For when the economic consequences of the pandemic, including a rise in unemployment, become apparent and thus also the stress in families increases - we must also expect increased violence in families [10] and consequently psychological reactions of children and adolescents [11].

From our point of view it is obvious that we have to act today in order not having to face our failures tomorrow and being responsible for the existence of a "lost generation".

\section{References}

1. Fegert JM, Vitiello B, Plener PL, Clemens V (2020) Challenges and burden of the Coronavirus 2019 (COVID-19) pandemic for child and adolescent mental health: a narrative review to highlight clinical and research needs in the acute phase and the long return to normality. Child Adolesc Psychiatry Ment Health 14(20). https://doi.org/10.1186/s13034-020-00329-3

2. Langmeyer A, Guglhör-Rudan A, Naab T, Urlen M, Winkelhofer U (2020) Kind sein in Zeiten von Corona. Ergebnisbericht zur Situation von Kindern während des Lockdowns im Frühjahr 2020. Deutsches Jugendinstitut. https://www.dji.de/fileadmin/user upload/bibs2020/Ergebnisbericht Kindsein Corona 2020.pdf

3. Ravens-Sieberer U, Kaman A, Otto C, Adedeji A, Devine J, Erhart M, Napp AK, Becker M, Blanck-Stellmacher U, Löffler C, Schlack R, Hurrelmann K (2020) Mental health and quality of life in children and adolescents during the COVID-19 pandemic - results of the COPSY study. Dtsch Arztebl Int 2020; 117: 828-9. https://doi.org/10.3238/arztebl.2020.0828

4. de Figueiredo CS, Sandre PC, Portugal LCL, Mázala-de-Oliveira T, da Silva Chagas L, Raony Í, Ferreira ES, Giestal-de-Araujo E, Dos Santos AA, Bomfim PO (2021) COVID-19 pandemic impact on children and adolescents' mental health: Biological, environmental, and social factors. Prog Neuropsychopharmacol Biol Psychiatry. 2021 Mar 2; 106: 110171. https://doi.org/10.1016/i.pnpbp.2020.110171

5. Andresen S, Lips A, Möller R, Rusack T, Schröer W, Thomas S, Wilmes J (2020) JuCo - Erfahrungen und Perspektiven von jungen Menschen während der CoronaMaßnahmen. Universitätsverlag Hildesheim. https://doi.org/10.18442/120

6. Bothe K, Schabus M, Eigl E-S, Hoedlmoser K (2021) How do Austrian children and adolescents sleep during the COVID-19 pandemic? Results from the "Jetzt sprichst Du!" survey. Manuscript in preparation.

7. Clift A K, Coupland C A C, Keogh R H, Diaz-Ordaz K, Williamson E, Harrison E M et al. (2020) Living risk prediction algorithm (QCOVID) for risk of hospital admission and 
mortality from coronavirus 19 in adults: national derivation and validation cohort study. BMJ 2020; 371. https://doi:10.1136/bmj.m3731

8. Berner R, Walger P, Simon A, Fischbach T, Dötsch J, Schneider, D, Huppertz H-I, Hübner J (2021) Stellungnahme der Deutschen Gesellschaft für Pädiatrische Infektiologie (DGPI) und der Deutschen Gesellschaft für Krankenhaushygiene (DGKH) zu Hospitalisierung und Sterblichkeit von COVID-19 bei Kindern in Deutschland. (Stand April 2021) Mortalität Kinder 21042021 korr (3).tiff (dgpi.de)

9. Pieh C, Plener PL, Probst T, Dale R, Humer E (2021) Mental health in adolescents during COVID-19-related social distancing and home-schooling. SSRN Electronic Journal. https://doi.org/10.2139/ssrn.3795639

10. Lee SJ, Ward KP, Lee JY, Rodriguez CM (2021) Parental social isolation and child maltreatment risk during the COVID-19 pandemic. J Fam Viol. https://doi.org/10.1007/s10896-020-00244-3

11. Ravens-Sieberer U, Kaman A, Erhart M, Devine J, Schlack R, Otto C (2021) Impact of the COVID-19 pandemic on quality of life and mental health in children and adolescents in Germany. Eur Child \& Adolesc Psychiatry. https://doi.org/10.1007/s00787-021-01726-5 